Pacific Journal of Mathematics

MATRIX TRANSFORMATIONS AND ABSOLUTE 


\title{
MATRIX TRANSFORMATIONS AND ABSOLUTE SUMMABILITY
}

\author{
Thomas A. KEAGY
}

The main results of this paper are two theorems which give necessary conditions for a matrix to map into $\ell$ the set of all subsequences (rearrangements) of a null sequence not in $\ell$. These results provide affirmative answers to the following questions proposed by J. A. Fridy. Is a null sequence $x$ necessarily in $\measuredangle$ if there exists a sum-preserving $\measuredangle-\ell$ matrix $A$ that maps all subsequences (rearrangements) of $x$ into $\ell$ ?

1. Introduction. Let $s, m, c, c_{0}$ and $c s$ denote, respectively, the set of all complex sequences, the set of all bounded sequences in $s$, the set of all convergent sequences in $s$, the set of all null sequences in $c$, and the set of all sequences in $s$ with sequence of partial sums in $c$. Let

$$
\zeta=\left\{x \in s: \Sigma\left|x_{p}\right|<\infty\right\} \text { and } \ell^{2}=\left\{x \in s: \Sigma\left|x_{p}\right|^{2}<\infty\right\} .
$$

A matrix $A$ which maps each element of $\ell$ into $\ell$ is called an $\iota-\ell$ matrix and may be characterized [3] and [6] by the property: $\left\{\sum_{p=1}^{\infty}\left|a_{p q}\right|\right\}_{q=1}^{\infty} \in m$. If, in addition, $\sum_{p=1}^{\infty} \sum_{q=1}^{\infty} a_{p q} x_{q}=\sum_{q=1}^{\infty} x_{q}$, whenever $x \in \ell$, then $A$ is a sum-preserving $\ell-\ell$ matrix; this is characterized by $\sum_{p=1}^{\infty} a_{p q}=1$, for each $q$.

In 1943, R. C. Buck [1] showed that a sequence $x$ is convergent if some regular matrix sums every subsequence of $x$. J. A. Fridy [5] has obtained an analog to Buck's theorem in which "subsequence" is replaced by "rearrangement." In addition, he has characterized $\ell$ by showing that $x \in \ell$ if there is a sum-preserving $\ell-\ell$ matrix that transforms every rearrangement of $x$ into $\ell$. In $\S 2$ of the present paper, necessary conditions are obtained for a matrix to map into $\ell$ the set of all subsequences of a null sequence not in Ł. This result yields as a corollary the affirmative answer to the following question proposed by J. A. Fridy [5]. Is a null sequence $x$ necessarily in $\ell$ if there exists a sum-preserving $\ell-\ell$ matrix that maps all subsequences of $x$ into $\ell$ ? In $\S 3$, necessary conditions are obtained for a matrix to map into $\ell$ all rearrangements of a null sequence not in $\ell$. This yields as a corollary Fridy's characterization of $\ell$ mentioned above. Finally, $\S 4$ contains examples of matrix mappings involving both subsequences and rearrangements.

2. Subsequences. The following two lemmas will be instru- 
mental in the proof of Theorem 1.

Lemma 1. Suppose $x$ and $a$ are sequences such that $\sum_{q=1}^{\infty} a_{q} y_{q}$ converges for every subsequence $y$ of $x$. If $\varepsilon>0$, then there exist $M>0$ and a strictly increasing function $\delta: I^{+} \rightarrow I^{+}$such that if $t>M$, then $\left|\sum_{q=t}^{\infty} a_{q} y_{q}\right| \leqq \varepsilon$ for every subsequence $\left(y_{q}\right)_{q=t}^{\infty}$ of $\left(x_{q}\right)_{q=\delta(t)}^{\infty}$.

Lemma 2. If $x$ is a null sequence not in $<$ and $a$ is a nonnull convergent sequence, then there exists a subsequence $y$ of $x$ such that $\lim _{t}\left|\sum_{q=1}^{t} y_{q}\right|=\infty$ and $\left(\sum_{q=1}^{n} a_{q} y_{q}\right)_{n=1}^{\infty}$ is not bounded.

THEOREM 1. Let $x$ be a null sequence not in $\ell$, and suppose $A$ is a matrix such that $A y \in \ell$ for every subsequence $y$ of $x$. Then

(i) $\sum_{p=1}^{\infty}\left|a_{p q}\right|<\infty$ for $q=1,2,3, \cdots$; and

(ii) if $\lim _{q} \sum_{p=1}^{\infty} a_{p q}=L$, then $L=0$.

Proof. To show (i), let $k$ be fixed and $j>i>k$ such that $x_{i} \neq x_{j}$. Let $y$ be the subsequence of $x$ such that $y_{q}=x_{q}$ for $q=$ $1,2, \cdots, k-1 ; y_{k}=x_{i}$; and $y_{k+t}=x_{j+t}$ for $t=1,2,3, \cdots$. Let $z$ be the subsequence of $x$ such that $z_{k}=x_{j}$ and $z_{q}=y_{q}$ otherwise. Then

$$
\infty>\sum_{p=1}^{\infty}\left|\sum_{q=1}^{\infty} a_{p q} y_{q}-\sum_{q=1}^{\infty} a_{p q} z_{q}\right|=\left|x_{i}-x_{j}\right| \sum_{p=1}^{\infty}\left|a_{p k}\right| \text {. }
$$

Therefore $\sum_{p=1}^{\infty}\left|a_{p k}\right|<\infty$.

Suppose $\lim _{q} \sum_{p=1}^{\infty} a_{p q}=L$ and $L \neq 0$. Let $\left(y_{1}, \cdots, y_{M-1}\right)$ be a subsequence of $x$ with $y_{M-1}=x_{r}$. Since $x \notin \ell$ there exists a subsequence $\left(w_{q}\right)_{q=M}^{\infty}$ of $\left(x_{q}\right)_{q=r+1}^{\infty}$ such that $\lim _{t}\left|\sum_{q=M}^{t} w_{q}\right|=\infty$. By Lemma 2 there exists a subsequence $\left(z_{q}\right)_{q=M}^{\infty}$ of $\left(w_{q}\right)_{q=M}^{\infty}$ such that $\lim _{t}\left|\sum_{q=M}^{t} z_{q}\right|=\infty$ and $\lim \sup _{t}\left|\sum_{q=M}^{t} z_{q} \sum_{p=1}^{\infty} a_{p q}\right|=\infty$. Choose $k>M$ such that

$$
\left|\sum_{q=M}^{k} z_{q} \sum_{p=1}^{\infty} a_{p q}\right|>M+\sum_{q=1}^{M-1}\left|y_{q}\right| \sum_{p=1}^{\infty}\left|a_{p q}\right|+3 .
$$

Let $K>0$ such that $\left|\sum_{p=K+1}^{\infty} a_{p q}\right|<1 /\left(k\left(\left|z_{q}\right|+1\right)\right)$ for $q=M, \cdots, k$. By Lemma 1 , letting $\varepsilon=1 / K$, there exist $N_{p}^{\prime}$ and $\delta_{p}^{\prime}$ for $1 \leqq p \leqq K$, such that if $N=\max \left\{N_{1}^{\prime}, \cdots, N_{K}^{\prime}, k+2\right\}$ and $\delta(i)=\max \left\{\delta_{p}^{\prime}(i): p=\right.$ $1, \cdots, K\}$, then $\sum_{p=1}^{K}\left|\sum_{q=N}^{\infty} a_{p q} v_{q}\right|<1$ for every subsequence $\left(v_{q}\right)_{q=N}^{\infty}$ of $\left(x_{q}\right)_{q=\delta(N)}^{\infty}$. Let $y_{q}=z_{q}$ for $M \leqq q \leqq k$, and choose $\left(y_{k+1}, \cdots, y_{N-1}\right)$ a subsequence of $\left(w_{q}\right)_{q=\delta(N)}^{\infty}$ such that $\sum_{q=k+1}^{N-1}\left|y_{q}\right| \sum_{p=1}^{\infty}\left|a_{p q}\right|<1$. Note that the first $N-1$ terms of a fixed sequence $y$ have now been determined. If $y^{*}$ is any subsequence of $x$ that agrees with $y$ for these first $N-1$ terms, then $\sum_{p=1}^{K}\left|\sum_{q=1}^{\infty} a_{p q} y_{q}^{*}\right|>M$.

This process for defining terms of $y$ may be continued so that if $T>0$, then there exist $M \geqq T$ and $K>0$ such that 


$$
\sum_{p=1}^{K}\left|\sum_{q=1}^{\infty} a_{p q} y_{q}\right|>M
$$

Thus a subsequence $y$ of $x$ can be constructed such jithat $A y \notin \ell$, a contradiction.

CoRollary 1. A null sequence $x$ is in $\ell$ if and only if there exists a sum-preserving $\measuredangle-\ell$ matrix $A$ such that $A y \in \ell$ for every subsequence $y$ of $x$.

3. Rearrangements. Following J. A. Fridy [5], the sequence $y$ is called a rearrangement of the sequence $x$ provided that there is a $1-1$ function $\pi$ from the positive integers onto themselves such that for each $k, x_{k}=y_{\pi(k)}$. The word "permutation" will be reserved to indicate the reordering of a finite sequence.

THEOREM. If $x$ is a null sequence not in $\measuredangle$ and $A$ is a matrix such that $A y \in \ell$ for every rearrangement $y$ of $x$, then $\lim _{q} \sum_{p=1}^{\infty}\left|a_{p q}\right|=0$.

Proof. Let $x_{i} \neq x_{j}$ be nonzero elements of $x$. Suppose the kth column of $A$ is not in $\ell$. Let $q \neq k$ and $y$ be a rearrangement of $x$ with $y_{k}=x_{i}$ and $y_{q}=x_{j}$. Let $z$ be the rearrangement of $x$ such that $z_{k}=x_{j}, z_{q}=x_{i}$, and $z_{t}=y_{t}$ otherwise. Then

$$
\left|x_{i}-x_{j}\right| \sum_{p=1}^{\infty}\left|a_{p l}-a_{p q}\right|=\sum_{p=1}^{\infty}\left|\sum_{q=1}^{\infty} a_{p q} y_{q}-\sum_{q=1}^{\infty} a_{p q} z_{q}\right|<\infty .
$$

Therefore $\sum_{p=1}^{\infty}\left|a_{p k}-a_{p q}\right|<\infty$ for every $q \neq k$. Since $\sum_{p=1}^{\infty}\left|a_{p k}\right|=\infty$, it now follows that $\sum_{p=1}^{\infty}\left|a_{p q}\right|=\infty$ for $q \geqq 1$. Suppose $N>0$ and a permutation $\left(r_{1}, \cdots, r_{M}\right)$ of $M$ terms of $x$ has been chosen such that $\sum_{q=1}^{M} r_{q} \neq 0$. If $\lambda=\sum_{p=1}^{\infty}\left|\sum_{q=1}^{M} a_{p q} r_{q}\right|<\infty$, then

$$
\infty>\lambda+\sum_{q=2}^{M}\left|r_{q}\right| \sum_{p=1}^{\infty}\left|a_{p 1}-a_{p q}\right| \geqq\left|\sum_{q=1}^{M} r_{q}\right| \sum_{p=1}^{\infty}\left|a_{p_{1}}\right|,
$$

a contradiction. Therefore $\lambda=\infty$ and there exists $K>N$ such that $\sum_{p=N}^{K}\left|\sum_{q=1}^{M} a_{p q} r_{q}\right|>2$. Let $i=\min \left\{q: x_{q} \in x \mid\left(r_{1}, \cdots, r_{M}\right)\right\}$. J. A. Fridy [5] has shown that each row of $A$ is null. Therefore there exists $T>M+1$ such that $\left|x_{i}\right| \sum_{p=1}^{K}\left|a_{p T}\right|<2^{-(M+1)}$. Let $r_{T}=x_{i}$ and $\left(r_{M+1}, \cdots, r_{T-1}\right)$ be a subsequence of $x \backslash\left(r_{1}, \cdots, r_{M}, r_{T}\right)$ such that $\sum_{p=1}^{K} \sum_{q=M+1}^{T-1}\left|a_{p q}\right|\left|r_{q}\right|<2^{-(M+2)}$ and $\sum_{q=1}^{T} r_{q} \neq 0$. Then

$$
\begin{aligned}
\sum_{p=N}^{K}\left|\sum_{q=1}^{T} a_{p q} r_{q}\right| \geqq & \sum_{p=N}^{K}\left|\sum_{q=1}^{M} a_{p q} r_{q}\right|-\sum_{p=N}^{K} \sum_{q=M+1}^{T-1}\left|a_{p q} r_{q}\right| \\
& -\left|r_{T}\right| \sum_{p=N}^{K}\left|a_{p T}\right|>1 .
\end{aligned}
$$


But this process may be continued. Therefore there exists a rearrangement $r$ of $x$ such that if $L>0$, then there exist $K>N \geqq L$ such that $\sum_{p=N}^{K}\left|\sum_{q=1}^{\infty} a_{p q} r_{q}\right|>1$, a contradiction. Hence each column of $A$ is in $\ell$.

Now suppose there exists $\varepsilon>0$ such that if $N>0$, then there exists $q>N$ such that $\sum_{p=1}^{\infty}\left|a_{p q}\right|>\varepsilon$. Let $z \in \ell$ be a subsequence of $x$ that includes all zero terms of $x$. Let $j_{1}=\min \left\{q: x_{q} \neq 0\right\}$. Let $N_{1}>0$ such that $\sum_{p=1}^{\infty}\left|a_{p_{1}}\right|>\varepsilon$. Let $r_{N_{1}}=x_{j_{1}}$. Also let $\left(r_{1}, \cdots, r_{N_{1}-1}\right)$ be a subsequence of $z$ such that $\sum_{q=1}^{N_{1}-1}\left|r_{q}\right| \sum_{p=1}^{\infty}\left|a_{p q}\right|<1 / 2$ and $z_{t}=r_{a}$ only if for each $s<t$ such that $z_{s}=0$ there exists $b<a$ such that $z_{s}=r_{b}$. Let $M_{1}>0$ such that

$$
\sum_{p=1}^{M_{1}}\left|a_{p_{N_{1}}}\right|>\frac{\varepsilon}{2} \text { and }\left|r_{N_{1}}\right| \sum_{p=M_{1}+1}^{\infty}\left|a_{p N_{1}}\right|<\frac{1}{4} .
$$

Let $j_{2}=\min \left\{q: x_{q} \in x \mid\left(r_{1}, \cdots, r_{N_{1}}\right)\right.$, and $\left.x_{q} \neq 0\right\}$. Since each row of $A$ is null, there exists $N_{2}>N_{1}+1$ such that $\sum_{p=M_{1}+1}^{\infty}\left|a_{p_{2}}\right|>\varepsilon / 2$ and $\left|x_{j_{2}}\right| \sum_{p=1}^{M_{1}}\left|a_{p_{2}}\right|<1 / 8$. Let $r_{N_{2}}=x_{j_{2}}$. Also let $\left(r_{N_{1}+1}, \cdots, r_{N_{2}-1}\right)$ be a subsequence of $z \backslash\left(r_{1}, \cdots, r_{N_{1}}, r_{N_{2}}\right)$ such that $\sum_{q=N_{1}+1}^{N_{2}-1}\left|r_{q}\right| \sum_{p=1}^{\infty}\left|a_{p q}\right|<1 / 16$ and $z_{t}=r_{a}$ only if for each $s<t$ such that $z_{s}=0$ there exists $b<a$ such that $z_{s}=r_{b}$. Let $M_{2}>M_{1}$ such that $\sum_{p=M_{1}+1}^{M_{2}}\left|a_{p_{2}}\right|>\varepsilon / 2$ and $\left|r_{N_{2}}\right| \sum_{p=M_{2}+1}^{\infty}\left|a_{p_{2}}\right|<1 / 32$. This selection process may be continued so that if $k$ is fixed, then

$$
\begin{aligned}
\sum_{p=1}^{M_{k}}\left|\sum_{q=1}^{\infty} a_{p q} r_{q}\right| \geqq & \left(\sum_{p=1}^{M_{1}}\left|a_{p N_{1}} r_{N_{1}}\right|+\cdots+\sum_{p=M_{k-1}+1}^{M_{k}}\left|a_{p N_{k}} r_{N_{k}}\right|\right) \\
& -\left(\sum_{q=1}^{N_{1}-1}\left|r_{q}\right| \sum_{p=1}^{M_{k}}\left|a_{p q}\right|+\sum_{p=M_{1}+1}^{M_{k}}\left|a_{p N_{1}} r_{N_{1}}\right|\right. \\
& +\sum_{q=N_{1}+1}^{N_{2}-1}\left|r_{q}\right| \sum_{p=1}^{M_{k}}\left|a_{p q}\right|+\left|r_{N_{2}}\right| \sum_{p=1}^{M_{1}}\left|a_{p N_{2}}\right| \\
& \left.+\sum_{p=M_{2}+1}^{M_{k}}\left|a_{p N_{2}} r_{N_{2}}\right|+\cdots\right) \geqq \frac{\varepsilon}{2} \sum_{i=1}^{k}\left|r_{N_{i}}\right|-1 .
\end{aligned}
$$

But $r$ has been selected so that $\lim _{k} \sum_{i=1}^{k}\left|r_{N_{i}}\right|=\infty$. Therefore $A r \notin \ell$, a contradiction. Hence $\lim _{q} \sum_{p=1}^{\infty}\left|a_{p q}\right|=0$.

The proof of Theorem 2 is now complete, and Corollary 2, which was first proved by J. A. Fridy [5], follows directly.

CoRollary 2. The null sequence $x$ is in $\ell$ if and only if there exists a sum-preserving $\measuredangle-\ell$ matrix $A$ such that $A y \in \ell$ for every rearrangement $y$ of $x$.

4. Examples. By Theorem 2 a matrix $A$ that maps all rearrangements of a sequence $x \in c_{0} \mid<$ into $\ell$ must be an $\ell-\ell$ matrix. 
But Theorem 1 gives little insight into the question of whether $A$ must be $\ell-\ell$ if it maps all subsequences of $x$ into $\ell$. The following example shows that $A$ need not be $\ell-\ell$ in this case. Let $x_{n}=1 / n$ for $n=1,2,3, \cdots ; a_{q q}=q^{1 / 3}$ for $q=1,8,27,64, \cdots$; and $a_{p q}=0$ otherwise. If $y$ is a subsequence of $x$ and $A y=z$, then $\left|z_{q}\right| \leqq q^{-2 / 3}$ for $q=1,8,27, \cdots$ and $z_{q}=0$ otherwise. Thus $z \in \ell$, but clearly $x \in c_{0} \mid<$ and $A$ is not $\ell-\ell$.

I. J. Maddox [7] showed that a matrix $A$ is Schur if it maps all subsequences of some divergent sequence $x$ into $c$. This might cause one to suspect that if $A$ maps all subsequences (rearrangements) of a sequence $x \in c_{0} \mid<$ into $\ell$, then $A z \in \ell$ for every $z \in c s$. The following example shows that this is not true. (The author wishes to thank the referee for his comments which aided in the simplification of this example.) Let $x_{n}=1 / n$ for $n=1,2,3, \cdots ; a_{1 q}=(-1)^{q} / q$ for $q \geqq 1$ and $a_{p q}=0$ otherwise. Since $\left(a_{1 q}\right)_{q=1}^{\infty}$ and $x$ are both in $\ell^{2}$, each subsequence (rearrangement) $y$ of $x$ is also in $\ell^{2}$; hence, $A y \in \ell$. But if $z$ is defined by $z_{q}=(-1)^{q} /(\log (q+1))$ for each $q$, then $z \in c s$ and $\left(a_{1 q} z_{q}\right)_{q=1}^{\infty} \notin c s$; thus, $A z \notin \ell$.

\section{REFERENCES}

1. R. C. Buck, A note to subsequences, Bull. Amer. Math. Soc., 49 (1943), 898-899.

2. - An addendum to " $A$ note on subsequences", Proc. Amer. Math. Soc., 7 (1956), 1074-1075.

3. J. A. Fridy, A note on absolute summability, Proc. Amer. Math. Soc., 20 (1969), $285-286$.

4. - Properties of absolute summability matrices, Proc. Amer. Math. Soc., 24 (1970), 583-585.

5. - Summability of rearrangements of sequences, Math. Z., 174 (1975), $187-192$.

6. Konrad Knopp and G. G. Lorentz, Beitrage zur absolutem Limitierung, Arch. Math., 2 (1949), 10-16.

7. I. J. Maddox, A Tauberian theorem for subsequences, Bull. London Math. Soc., 2 (1970), 63-65.

Received October 23, 1975.

WAYLAND Baptist COLLEgE 



\title{
PACIFIC JOURNAL OF MATHEMATICS
}

\author{
EDITORS
}

\author{
RICHARD ARENS (Managing Editor) \\ University of California \\ Los Angeles, California 90024
}

\author{
R. A. Beaumont \\ University of Washington \\ Seattle, Washington 98105
}

J. DugundjI

Department of Mathematics

University of Southern California

Los Angeles, California 90007

D. Gilbarg and J. Milgram

Stanford University

Stanford, California 94305

\section{ASSOCIATE EDITORS}
E. F. BECKENBACH
B. H. NEUMANN
F. WOLF
K. Yoshida

\section{SUPPORTING INSTITUTIONS}

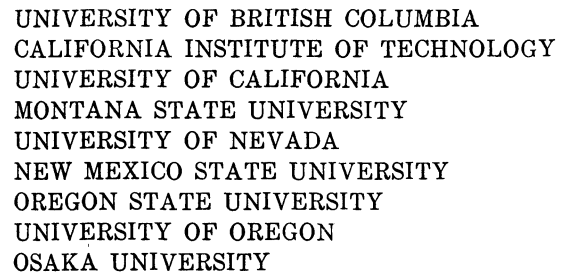

UNIVERSITY OF BRITISH COLUMBIA CALIFORNIA INSTITUTE OF TECHNOLOGY UNIVERSITY OF CALIFORNIA MONTANA STATE UNIVERSITY UNIVERSITY OF NEVADA NEW MEXICO STATE UNIVERSITY OREGON STATE UNIVERSITY UNIVERSITY OF OREGON OSAKA UNIVERSITY

\author{
UNIVERSITY OF SOUTHERN CALIFORNIA \\ STANFORD UNIVERSITY \\ UNIVERSITY OF HAWAII \\ UNIVERSITY OF TOKYO \\ UNIVERSITY OF UTAH \\ WASHINGTON STATE UNIVERSITY \\ UNIVERSITY OF WASHINGTON

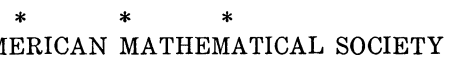

The Supporting Institutions listed above contribute to the cost of publication of this Journal, but they are not owners or publishers and have no responsibility for its content or policies.

Mathematical papers intended for publication in the Pacific Journal of Mathematics should be in typed form or offset-reproduced, (not dittoed), double spaced with large margins. Please do not use built up fractions in the text of your manuscript. You may however, use them in the displayed equations. Underline Greek letters in red, German in green, and script in blue. The first paragraph or two must be capable of being used separately as a synopsis of the entire paper. Items of the bibliography should not be cited there unless absolutely necessary, in which case they must be identified by author and Journal, rather than by item number. Manuscripts, in triplicate, may be sent to any one of the editors. Please classify according to the scheme of Math. Reviews, Index to Vol. 39. All other communications should be addressed to the managing editor, or Elaine Barth, University of California, Los Angeles, California, 90024.

The Pacific Journal of Mathematics expects the author's institution to pay page charges, and reserves the right to delay publication for nonpayment of charges in case of financial emergency.

100 reprints are provided free for each article, only if page charges have been substantially paid. Additional copies may be obtained at cost in multiples of 50 .

The Pacific Journal of Mathematics is issued monthly as of January 1966. Regular subscription rate: $\$ 72.00$ a year (6 Vols., 12 issues). Special rate: $\$ 36.00$ a year to individual members of supporting institutions.

Subscriptions, orders for back numbers, and changes of address should be sent to Pacific Journal of Mathematics, 103 Highland Boulevard, Berkeley, California, 94708.

PUBLISHED BY PACIFIC JOURNAL OF MATHEMATICS, A NON-PROFIT CORPORATION

Printed at Kokusai Bunken Insatsusha (International Academic Printing Co., Ltd.), 8-8, 3-chome, Takadanobaba, Shinjuku-ku, Tokyo 160, Japan.

Copyright (C) 1975 by Pacific Journal of Mathematics Manufactured and first issued in Japan 


\section{Pacific Journal of Mathematics}

\section{Vol. 63, No. 2 \\ April, 1976}

Joseph Anthony Ball and Arthur R. Lubin, On a class of contractive perturbations

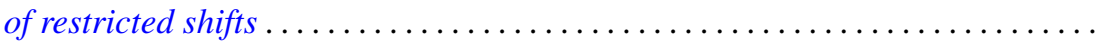

Joseph Becker and William C. Brown, On extending higher derivations generated

by cup products to the integral closure .......................

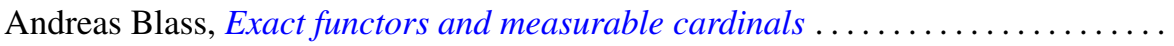

Joseph Eugene Collison, A variance property for arithmetic functions . . . . . . . . . .

Craig McCormack Cordes, Quadratic forms over nonformally real fields with a

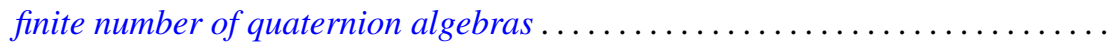

Freddy Delbaen, Weakly compact sets in $H^{1} \ldots \ldots \ldots \ldots \ldots \ldots \ldots \ldots \ldots$

G. D. Dikshit, Absolute Nörlund summability factors for Fourier series ..........

Edward Richard Fadell, Nielsen numbers as a homotopy type invariant. . ........

Josip Globevnik, Analytic extensions of vector-valued functions . . . . . . . . . . . .

Robert Gold, Genera in normal extensions . . . . . . . . . . . . . . . . . . . 389

Solomon Wolf Golomb, Formulas for the next prime

Robert L. Griess, Jr., The splitting of extensions of $S L(3,3)$ by the vector space

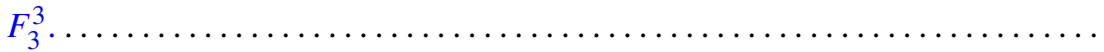

Thomas Alan Keagy, Matrix transformations and absolute summability .........

Kazuo Kishi, Analytic maps of the open unit disk onto a Gleason part.

Kwangil Koh, Jiang Luh and Mohan S. Putcha, On the associativity and commutativity of algebras over commutative rings . ..... . .

James C. Lillo, Asymptotic behavior of solutions of retarded differential difference equations.

John Alan MacBain, Local and global bifurcation from normal eigenvalues ..

Anna Maria Mantero, Sets of uniqueness and multiplicity for $L^{p}$

J. F. McClendon, Embedding metric families

L. Robbiano and Giuseppe Valla, Primary powers of a prime ideal .

Wolfgang Ruess, Generalized inductive limit topologies and barrelledness

properties.

Judith D. Sally, Bounds for numbers of generators of Cohen-Macaulay ideals

Helga Schirmer, Mappings of polyhedra with prescribed fixed points and fixed point indices.

Cho Wei Sit, Quotients of complete multipartite graphs

S. Sznajder and Zbigniew Zielezny, Solvability of convolution equations in $\mathscr{K}_{p}^{\prime}$,

$p>1$.

Mitchell Herbert Taibleson, The existence of natural field structures for finite

dimensional vector spaces over local fields

William Yslas Vélez, A characterization of completely regular fields

P. S. Venkatesan, On right unipotent semigroups ..............

Kenneth S. Williams, A rational octic reciprocity law ............

Robert Ross Wilson, Lattice orderings on the real field .......... 